\title{
Health implications of fructose consumption: A review of recent data
}

\author{
Salwa W Rizkalla ${ }^{1,2}$
}

\begin{abstract}
This paper reviews evidence in the context of current research linking dietary fructose to health risk markers. Fructose intake has recently received considerable media attention, most of which has been negative. The assertion has been that dietary fructose is less satiating and more lipogenic than other sugars. However, no fully relevant data have been presented to account for a direct link between dietary fructose intake and health risk markers such as obesity, triglyceride accumulation and insulin resistance in humans. First: a re-evaluation of published epidemiological studies concerning the consumption of dietary fructose or mainly high fructose corn syrup shows that most of such studies have been cross-sectional or based on passive inaccurate surveillance, especially in children and adolescents, and thus have not established direct causal links. Second: research evidence of the short or acute term satiating power or increasing food intake after fructose consumption as compared to that resulting from normal patterns of sugar consumption, such as sucrose, remains inconclusive. Third: the results of longer-term intervention studies depend mainly on the type of sugar used for comparison. Typically aspartame, glucose, or sucrose is used and no negative effects are found when sucrose is used as a control group.

Negative conclusions have been drawn from studies in rodents or in humans attempting to elucidate the mechanisms and biological pathways underlying fructose consumption by using unrealistically high fructose amounts.

The issue of dietary fructose and health is linked to the quantity consumed, which is the same issue for any macro- or micro nutrients. It has been considered that moderate fructose consumption of $\leq 50 \mathrm{~g} /$ day or $\sim 10 \%$ of energy has no deleterious effect on lipid and glucose control and of $\leq 100 \mathrm{~g} /$ day does not influence body weight. No fully relevant data account for a direct link between moderate dietary fructose intake and health risk markers.
\end{abstract}

\section{Introduction}

Fructose, a natural sugar found in many fruits, is consumed in significant amounts in Western diets [1]. In equal amounts, it is sweeter than glucose or sucrose and is therefore commonly used as a bulk sweetener.

An increase in high fructose corn syrup, as well as total fructose, consumption over the past 10 to 20 years has been linked to a rise in obesity and metabolic disorders [2]. This raises concerns regarding the short and long term effects of fructose in humans.

\section{Why is fructose of concern?}

Fructose has been claimed to be of concern due to several factors: First, in the 1980's, sucrose was replaced to

\footnotetext{
Correspondence: salwa.rizkalla@psl.aphp.fr

${ }^{1}$ INSERM, U872, équipe 7 Nutriomique, Université Pierre et Marie Curie-Paris 6, Centre de Recherche des Cordeliers, UMR S 872, Paris, 75006 France
}

Full list of author information is available at the end of the article a large extent, particularly in North America, by high fructose corn syrup (HFCS) in carbonated beverages. The intake of soft drinks containing HFCS has risen in parallel with the epidemic of obesity [3]. Second, dietary fructose has been implicated in risk factors for cardiovascular disease (CVD): 1. Plasma triglycerides (TG) and VLDL-TG increased following the ingestion of large quantities of fructose; 2. Fructose intake has been found to predict LDL particle size in overweight schoolchildren [4]; 3. A positive relationship has been demonstrated between fructose intake and uric acid levels [5]. Third, the use of fructose as a sweetener has increased. The third National Health Examination Survey (NHANES) demonstrated that over 10\% of Americans' daily calories were from fructose [6]. These studies suggest that the relationship between fructose and health needs re-evaluation.
C Biomed Central

(c) 2010 Rizkalla; licensee BioMed Central Ltd. This is an Open Access article distributed under the terms of the Creative Commons Attribution License (http://creativecommons.org/licenses/by/2.0), which permits unrestricted use, distribution, and reproduction in any medium, provided the original work is properly cited. 


\section{Fructose consumption and body weight}

Lipogenesis from fructose consumption may theoretically be greater than that induced after eating other types of sugars such as glucose and sucrose [7]. But could this be physiologically true?

\section{Evidence from experimental studies in animals}

The evidence of the action of dietary fructose, but not glucose, on increasing appetite and food intake in acuteterm studies has been derived mainly from experimental studies in animals. Although glucose and fructose utilize the same signaling pathway to control food intake, they act in an inverse manner and have reciprocal effects on the level of the hypothalamic malonyl-CoA, a key intermediate in the hypothalamic signal cascade that regulates energy balance in animals [8]. When injected into the cerebroventricles of rats, fructose has been found to induce increase in food intake via a reduction of hypothalamic malonyl-CoA levels, whereas similar concentrations of injected glucose increased malonyl- CoA suppressing appetite-agonist and food intake [9]. The rapid initial steps of central fructose metabolism deplete hypothalamic ATP level, whereas the slower regulated steps of glucose metabolism elevate hypothalamic ATP level. Consistent with its effects on the $[\mathrm{ATP}] /[\mathrm{AMP}]$ ratio, fructose increases phosphorylation/activation of hypothalamic AMP kinase causing phosphorylation/ inactivation of acetyl-CoA carboxylase, whereas glucose mediates the inverse effects.

The question has been raised as to whether fructose may induce the same effects if presented in the systemic circulation and not injected directly in the brain. Consequently, Cha et al [10], demonstrated that when glucose was administered intra-peritoneally, hence entered the systemic circulation, it was rapidly metabolized by the brain, increasing the level of hypothalamic malonyl-CoA. Fructose administration, however, had the opposite effect on malonyl-Co-A and food intake. Such a finding might appear to set off another alarm bell about the problems of dietary fructose. However, closer inspection reveals that the latter study used only 4 mice, which were injected with a dose of $4 \mathrm{~g} / \mathrm{Kg}$ of body weight, a dose too large to be considered relevant to human nutrition. While this paper demonstrated that high doses of fructose and glucose acted on different pathways, the physiological significance of these results remains unclear. Fructose ingestion is unlikely to increase fructose levels in the cerebrospinal fluid, and plasma fructose levels will never exceed the micromolar range under physiological conditions. Some authors suggested the uncertainty of these effects [11]. Therefore, no evidence of cause for health concern could be drawn from such acute studies in rodents.
The effects of fructose on body weight were further questioned. When rats were fed a high fructose diet (60\%) for 6 months then switched to a high fat diet for 2 weeks, leptin levels increased and a state of leptin resistance was found prior to increased adiposity and body weight induced by the high fat diet [12]. However, in other shorter term studies (3-6 weeks) high fructose feeding (57\% in weight) induced insulin resistance and hypertriglyceridemia in rats but failed to induce an increase in body weight [13-15].

Thus, in rodents while excessively high fructose intake may increase appetite by different mechanisms, its' effect on body weight needs long term dietary periods.

\section{Acute studies in humans: fructose, food intake and satiety}

Sugars and sugar sweetened beverages have been blamed for causing obesity, but the debate has raged for many years with little resolution [16]. More recently, the intensity of the debate was fuelled by the hypothesis that HFCS lead to obesity because fructose bypasses food intake regulatory system (insulin and leptin) and favors lipogenesis [17]. It was hypothesized that energy containing drinks, especially those sweetened with HFCS promotes energy imbalance and thereby play a role in the development of obesity. In an acute-term study [17], 12 normal -weight women consumed meals containing 55,30 or $15 \%$ of total calories as carbohydrate, fat and proteins with $30 \%$ of Kcal as either fructose sweetened or glucose sweetened beverages. As expected, glucose excursions and insulin secretion were lower after fructose meals than after glucose ones. This was associated to a decrease in leptin levels, which is an expected consequence of lowering insulin levels. It is important to notice that the reduction in leptin levels remained within physiological normal levels and fluctuated between: $9 \mathrm{ng} / \mathrm{ml}$ during the morning and $19.8 \mathrm{ng} /$ $\mathrm{ml}$ by night. After this acute- term study, following only one meal, the authors rapidly suggested that because insulin and leptin (the main regulatory factors of food intake) were lower after fructose meals; they might increase caloric intake and ultimately contribute to weight gain and obesity. Fructose meals should be compared to sucrose the usual sugar and not to glucose which gives extreme levels.

The question was then raised whether HFCS has different effect on satiety than other isoenergetic drinks as sucrose or milk; again this question was investigated in an acute study. In order to have a simple response Soenen and Westerterp [18] compared the satiating effects of $4800 \mathrm{ml}$ of HFCS, sucrose and milk containing each $1.5 \mathrm{MJ}$ in comparison with a diet drink with no energy. They measured satiety by a visual analogue scale and by 
determining the satiety hormones (leptin and ghrelin) concentrations. They concluded that energy balance consequences were the same between the three isoenergetic drinks evaluated. Therefore, fructose in term of satiety is not different from that of usually consumed sugar and even that of another isocaloric drink (milk).

In another study Akhavan et al [19] aimed to evaluate whether HFCS in soft drinks is different from sucrose solutions. They compared solutions containing sucrose, HFCS, or various ratios of glucose to fructose (G50:F50) on food intake, average appetite and on plasma concentrations of glucose, insulin and ghrelin. Measurements were taken from base line to 80 minutes only. The authors of the latter paper concluded that all the solutions tested do not have significantly different effects on subjective and physiologic measures of satiety at a subsequent meal. Therefore, there is no solid evidence that sucrose, when consumed in its intact form, would confer any benefits over HFCS, which contains the 2 unbound monosaccharides.

Similarly, in a 24 hour study Stanhope 2008 [20] and Melanson [21] did not find substantially different effects between meals with either sucrose or HFCS on 24 hour plasma glucose, insulin, leptin and ghrelin levels. Even TG profiles were found to be similar between the two tests. These responses were found to be intermediate between the lower responses after the pure fructose syrup consumption and the higher responses after glucose solution ingestion. There was no difference in food intake during a meal consumed $50 \mathrm{~min}$ later or in the components of food intake regulatory mechanisms.

\section{Chronic studies in humans}

Although acute fructose consumption could not stimulate leptin secretion, an increase in fasting leptin levels was detected after chronic high fructose intake (1 to 4 weeks) in healthy individuals, which may suggest that high fructose feeding may suppress food intake in the long term [22]. Another long term study in overweight/ obese humans showed no change in body weight after 10 week-supplementation with glucose or fructose, indicating that the effect of fructose or glucose on food intake might not differ on long term bases [23].

In a cluster randomized controlled study [24], the effect of a focused educational intervention program on carbohydrate sweetened beverage consumption and overweight was studied using 644 children (7-11 years old). Children participated in a program designed to emphasize the consumption of a balanced diet and to discourage the consumption of sweetened drinks (mainly by sucrose: glucose/fructose). Sweetened drink consumption decreased in the intervention group and increased in the control one. Parallel changes in BMI occurred in each group, but without any difference between the two groups. Therefore, no conclusion could be given on appetite or body weight even if fructose is present as a part of sucrose.

\section{Epidemiological studies}

The recent epidemiological study of Vos et al [6] created new concern in regards to fructose consumption. These authors analyzed data from the US population who had participated in the NHANES III study, collected from 1988 to 1994 . 21,483 adults and children 2 years of age or older were included in this study. Investigators found that fructose consumption had increased to $54.7 \mathrm{~g} / \mathrm{d}$ (10.2\% of total caloric intake), compared to $37 \mathrm{~g} / \mathrm{d}(8 \%)$ of total intake in 1977-1978. The consumption was highest among adolescents (12-18 years) at $72.8 \mathrm{~g} / \mathrm{d}$ (12.1\% of total calories). They showed that over $10 \%$ of Americans' daily calories were from fructose [6].

Bray et al [25] suggested that the increase in obesity in the last 35 years has paralleled the increasing use of high-fructose corn syrup (HFCS), which first appeared just before 1970. Current soft drinks and many other foods are sweetened with this product because it is inexpensive and has useful manufacturing properties. The fructose in HFCS and sugar makes beverages very sweet, and this sweetness may underlie the relationship between obesity and soft drink consumption. Indeed in the United States, HFCS has increasingly replaced sucrose in many foods and sweetened beverages, a fact that might appear to strengthen the hypothesis that there is a relationship between fructose and obesity. The parallelism between the increase in the consumption of high fructose corn syrup and dietary fructose and the rise in obesity over the past 10-20 years, linked fructose to the rise in obesity and metabolic disorders, mainly in the United States.

This is not the case in Europe or outside the United states, where fructose is consumed mainly from sucrose and fructose consumption is linked mainly to sugar consumption. Moreover, the evidence from metabolism studies on fructose alone is irrelevant to the HFCS and weight gain debate. Most of the studies dealing with the causes of obesity and over-weight have centered on HFCS [26].

\section{Cross-sectional studies}

In a cross sectional study, when correlating the BMI of the NHANES 1988-1994 cohort to the results of 24 hour dietary recall and one food frequency questionnaire by a multivariate regression model, a positive association was found between consumption of carbonated soft drinks and the BMI of females [27]. Using a continuing survey of food intake for individuals (CSFII) in another cross-sectional study, Forshee et al [28] found that BMI had a statistically positive relationship with diet carbonated soft drink consumption for both boys 
and girls $(\mathrm{n}=1749)$ children $(6-11$ years $)$ and adolescents (12-19 years). Other cross-sectional studies in American children demonstrated a positive correlation between soft drinks and BMI [29,30]. When looking at Pacific Island children living in New Zealand, where HFCS is very limited, the consumption of sucrose has been evaluated and correlated to body weight. The obese children consumed more of all types of food with no difference between obese and non obese children's consumption patterns [30].

Most of the cross-sectional studies included no controls for sedentary behaviors, physical activity, and energy intake from other sources other than beverages in the model. Moreover, in these studies BMI and beverage consumption were self-reported and hence subject to measurements errors. Causal relationship cannot be made from cross-sectional study design.

In longitudinal epidemiologic studies, such as the US Growing Up Today Study (GUTS) in a cohort of more than 10,000 males and females (9-14 years in 1996), authors did not find a correlation between BMI and snack food consumption, including sugar-sweetened beverages [31] when controlling for total energy [32]. In the North Dakota Special Supplemental Nutrition Program for Women, Infants, and Children (WIC) [33], no significant association was detected between any of the beverages evaluated and BMI. Even in another study among 30 children aged 6-13 years attending the Cornell Summer Day in 1997 [34], excessive sweetened drink consumption ( $>370 \mathrm{~g} /$ day) did not correlate with weight gain. Again results of these longitudinal studies are not conclusive. Most of the positive correlations presented disappeared when corrected by total energy.

Meta-analysis linking soft drink consumption and body weight demonstrated conflicting results. One meta-analysis of 12 studies in children and adolescents [35] failed to find a positive association between soft drink consumption and body weight, where as another meta-analysis dealing with 88 studies found an association [36].

\section{Conclusion}

The relation between HCFS and obesity has been derived mainly from epidemiological studies trying to relate the increase in consumption of dietary fructose and HFCS on one hand and to the increase in obesity (see ref [37]. In the epidemiological, cross -sectional and longitudinal studies, the overall evidence for a positive correlation between consumption of soft drinks and overweight is limited. Causal inferences cannot be made from cross-sectional study designs with values subjected to measurement error. The interventional acute studies (24 hours) found that fructose is thought to be associated with insufficient secretion of insulin and leptin and suppression of ghrelin when compared with pure glucose. Such a difference, however, could not be demonstrated when HFCS compared with sucrose, the commonly consumed sweetener. In addition appetite and energy intake do not differ in the acute-term. There are no long-term interventional studies investigating the direct relationship between HFCS and body weight [38], with the exception of Tordoff et al [39] who compared the consumption of 4 bottles of soda/day (1135g) as HFCS or as soda sweetened with aspartame for 3 weeks. Unsurprisingly, subjects who consumed the HFCS as extra calories gained more weight than those consuming the soda with aspartame. There is evidence that body weight increases when calorie intake is in a positive balance, regardless of whether this is due to HCFS, fat, proteins or any other form of calories. Moreover, in a recent meta-analysis, no significant effect of fructose consumption could be demonstrated on body weight with doses $\leq 100 \mathrm{~g} /$ day in adults [40]. Unfortunately the recent focus on HFCS has done little to resolve the role of sugars in contributing to energy imbalance.

Meanwhile, a positive effect of fructose on satiety was demonstrated in the 1990's. The group of Rodin et al [41-43] demonstrated that the intake of $50 \mathrm{~g}$ fructose alone as the sole source of carbohydrate, either in solution or in the form of puddings 2 hours 25 minutes before a meal, caused a decrease in appetite and lipid intake. Therefore, this could even be used as an adjunct to weight control efforts.

\section{Important points}

It is clear that fructose is poorly absorbed from the digestive tract when it is consumed alone. However, absorption improves when fructose is consumed in combination with glucose and amino acids [44]. In addition, the principal sweetener in soft drinks in the US, HFCS, is not pure fructose but a mixture of fructose (55\%) and glucose (45\%). HFCS is predominately present as HFCS-55 (55\% fructose, $41 \%$ glucose, and $4 \%$ glucose polymers) or HFCS-42 (42\% fructose, $53 \%$ glucose and $5 \%$ glucose polymers) [26]. Therefore, the term "high fructose corn syrup" is not a good descriptor of its composition, but the term was mandated to distinguish the newly developed fructose-containing corn syrup from traditional all-glucose corn syrups. Factors that may account for the different effects of fructose alone or a mixture of fructose and glucose could be its gastrointestinal effects and absorption characteristics [45].

It should also be noted that even in a study that increased further the concerns about fructose intake [4], which looked at overweight Swiss children, the authors could not demonstrate any correlation between fructose intakes and adiposity or any other lipid variables in children (cholesterol, triglycerides), with the exception of LDL particle's size. 
Clearly fructose itself is not driving the obesity epidemic, but there is evidence supporting the possibility that refined carbohydrates in general could have a contributory role, if not a major one. Very recently, this problem has been attributed to all added sugars (highfructose corn syrup or fruit-juice concentrates), and not only added fructose [46].

Fructose intake as well as HFCS may be a contributor, but it's not the sole problem. Obese subjects consume too many calories for their activity level, including too much fat, protein and sugar. It is clear that energy imbalance for most individuals is caused by energy intake exceeding expenditure. A dietary solution to obesity remains elusive, but focusing on reducing one food item is unlikely to succeed $[47,48]$. Moreover, overweight and obesity are influenced by many genetic [49-51] and environmental factors [52]: for instance:

a) promoting water consumption can prevent overweight among children in elementary school [53]; b) habituation on behavioral and physiological responses to repeated presentations of food [54]; c) addressing specific eating patterns [55] and d) efforts to reduce fast food portion size [56].

Whatever the cause of obesity, based on the currently available evidence, an expert panel formed by the Centre of Food Nutrition and Agriculture Policy concluded that HFCS does not appear to contribute to overweight and obesity any differently than other energy sources [26].

\section{Fructose, lipogenesis and cardiovascular risk factors}

Another concern with fructose intake is that it may induce hypertriglyceridemia and lipogenesis. Theoretically, fructose consumption can result in increasing TG synthesis [57].

\section{Intestinal absorption}

fructose is absorbed from the intestine via glucose transporters 5 (GLUT 5), then it diffuses into the blood vessels through GLUT 2 or 5 [58], but mainly by GLUT 2. Contrary to glucose, fructose absorption from the intestinal lumen does not require ATP hydrolysis and is independent of sodium absorption, which results in massive fructose uptake by the liver [59].

\section{Hepatic metabolism (Figure 1)}

The hepatic metabolism of fructose differs also greatly from that of glucose. Contrary, to glucose, fructose is metabolised exclusively in the liver by fructokinase $(\mathrm{Km}$ : $0.5 \mathrm{mM}$ ). Glucose, however, tends to be transported to the liver but could be metabolized anywhere in the body by glucokinase ( $\mathrm{Km}$ of hepatic glucokinase: $10 \mathrm{mM}$ ).

In the liver glucose is first phosphorylated by glucokinase to give glucose-6-phosphate, which is then converted to fructose -6-phosphate, and further to fructose 1,6-bisphosphate. This process is regulated by the ratelimiting enzyme phosphofructokinase, which in inhibited

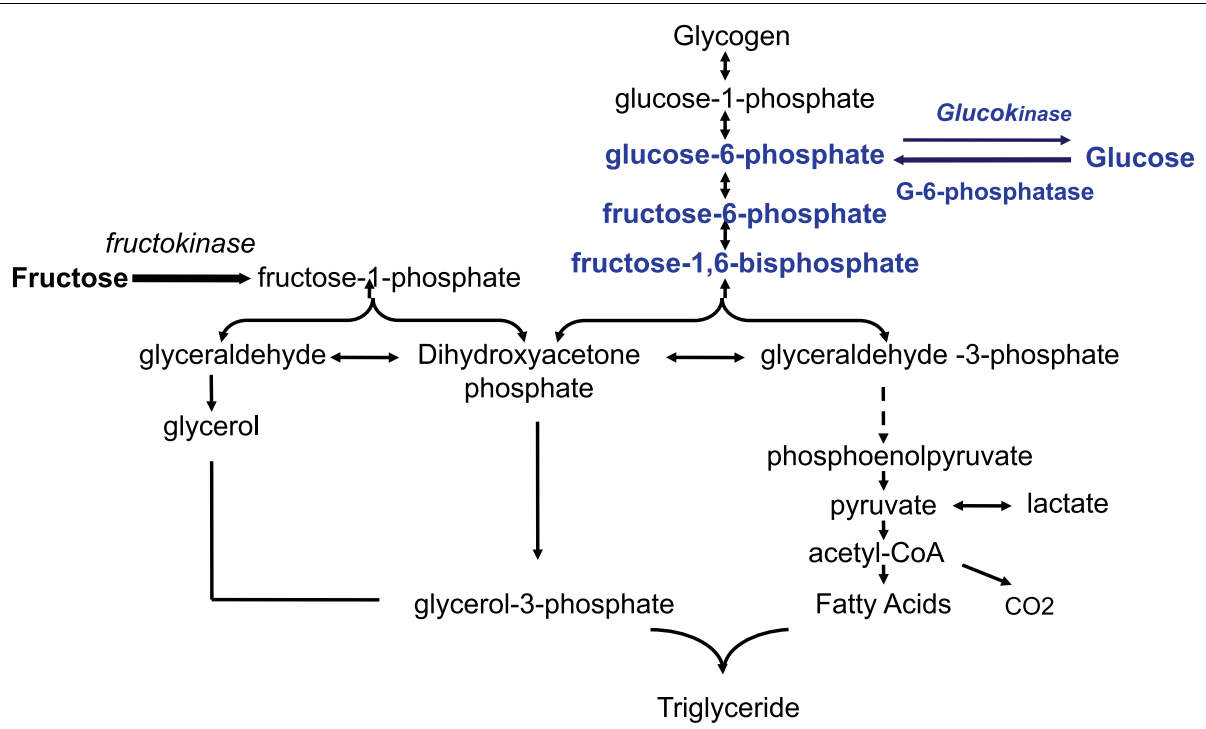

Figure 1 Fructose and glucose metabolism in liver cells: After several steps glucose is converted into fructose1,6-bi-phosphate. A reaction regulated by the rate-limiting enzyme phosphofructokinase, which is inhibited by ATP and citrate. Altogether the conversion of glucose to pyruvate is regulated by insulin. On the other hand, fructose, is massively taken by the liver, and converted rapidly to triose-phosphate independently of insulin control and without a feedback by ATP or citrate. A large portion of fructose is converted into glucose which can be released in the blood or stored as glycogen. A part is converted into lactate. A small portion is converted into fatty acids, which may play an important role in the development of hypertriglyceridemia and fatty liver. 
by ATP and citrate. Fructose 1,6-bisphosphate is converted into pyruvate prior to entry into the Krebs cycle. The hepatic conversion of glucose to pyruvate is regulated by insulin.

In contrast, the conversion of fructose into triosePhosphate is a rapid process independent of insulin. Fructose bypasses the main regulatory step of glycolysis (the conversion of glucose-6-phosphate to fructose 1,6bisphosphate controlled by phosphofructokinase) and hence can continuously enter the glycolytic pathway. This rapidity is due mainly to the low $\mathrm{Km}$ of fructokinase for fructose, and the absence of negative feedback by ATP or citrate [60]. A portion of triose-phosphate produced from fructose can subsequently be converted into pyruvate and oxidized into $\mathrm{CO} 2$ and water. Another portion is converted into lactate to be released into the circulation [61]. The major portion of the triose-phosphate produced from fructose is converted into glucose and glycogen through gluconeogenesis [62]. At the end, part of the carbons from fructose can be converted to fatty acids. Simultaneously, fructose inhibits hepatic lipid oxidation favouring fatty acid reesterification and VLDL-triglyceride synthesis [63]. Therefore, fructose can rapidly and without any control produce glucose, glycogen, lactate, and pyruvate, providing both the glycerol and acyl portion of acyl-glycerol molecules. These particular substrates and the lack of regulation of this pathway could result in large amounts of TG that can be packed into very-low density lipoproteins by the liver.

It is essential to note that the general disposition of fructose carbon between its major end products is modified by nutritional and endocrine status [64]. Once fructose has been catabolized to three-carbon molecules its subsequent metabolic fate is identical to that of glucose. Hence, fructose can also be converted to glycogen once a positive energy balance has been established. On the other hand, glucose is mainly stored as glycogen in the liver, but high glucose levels may increase formation of glycerol -3 phosphate and accelerate hepatic triglyceride production [65].

\section{TG Clearance}

Moreover, as VLDL goes into the bloodstream, these TG can be hydrolyzed by lipoprotein lipase (LPL) into non-estrified fatty acids and monoacylglycerol. These components could be taken by adipose tissue to resynthesise TG. However, fructose consumption does not lead to insulin stimulation resulting then in low insulin excursions that may affect LPL-stimulated lipolysis and thus contribute to reduced TG clearance. Therefore, fructose consumption has been suggested to induce both increased hepatic TG that can be packed into verylow density lipoproteins by the liver and reduced TG clearance by adipose tissue.

\section{Intestinal origin of TG}

Fructose-induced hyperlipidemia has been also hypothesized to be of intestinal origin. Jeppesen et al [66] demonstrated that the addition of $50 \mathrm{~g}$ fructose to an oral fat load ( $40 \mathrm{~g}$ ) resulted in higher postprandial concentrations of triglycerides and retinyl palmitate in plasma and lipoprotein fraction (of intestinal origin). These results were found to be more pronounced with high fasting plasma triglyceride concentrations. The increase in plasma TG induced by high fructose diet in hamsters, was demonstrated to originate from fructose conversion into fatty acids within the enterocytes, with overproduction of apoB-48-containing lipoprotein $[67,68]$.

\section{Evidence from experimental studies in animals}

Evidence of fructose induced lipogenesis comes mainly from studies in rodents [69,70]. In fact, evidence exists that consuming large amounts of fructose leads to the development of a complete metabolic syndrome in rodents [71-73].

In the liver, the ability to metabolize fructose more rapidly than glucose into different metabolites has been demonstrated in rats [74]. The ratio of fructose metabolism/glucose metabolism (F/G) varies between a minimum of 3 for lactic acid, pyruvic acid, $\mathrm{CO} 2$ and free fatty acids, and a maximum of 19 for glyceraldehydeglycerol.

On the other hand, it has been demonstrated that feeding rats with $75 \%(\mathrm{w} / \mathrm{w})$ fructose or glucose diets increased the capacity for triglyceride formation from glycerol-3-phosphate by rat liver homogenates and increased incorporation of [1,3-14C] glycerol into hepatic TG by the intact animal [65]. Hepatic TG production changed with a similar time-course characteristic for each diet. However, the $75 \%$ fructose diet produced a greater increase in both determinations, reaching a maximum after 11 days. Despite the increase in hepatic TG formation by both high-sugar diets, only the $75 \%$ fructose diet resulted in a consistent and sustained increase in serum TG. These results were suggested to be due to differences in the fractional rate of serum TG removal between the two groups. The authors proposed that high glucose intake most likely produces an early acceleration in the fractional rate of TG removal that fully compensates for any increased production, which could be related to increased insulin stimulated-adipose tissue lipoprotein lipase activity [75] and accelerated adipose tissue lipogenesis [76-78]. This is not the case with fructose, which does not stimulate insulin secretion.

Studies dealing with mechanisms underlying fructoseinduced lipogenesis provided sufficient evidence in animals [79]. Enzymes implicated in hepatic lipogenesis 
were found to be increased by high fructose diets: Seven days on $60 \%$ fructose diet [80] induced an increase in hepatic sterol regulatory element binding protein (SREBP-1) expression, which is a key transcription factor responsible for regulating fatty acid and cholesterol biosynthesis, as wall as lipogenic gene expression including fatty acid synthase (FAS) and acetyl Co-A carboxylase in mice. It is of interest that glucose feeding could induce, via insulin stimulation, a short-term peak induction of SREB, whereas fructose caused gradual increasing of SREBP-1c activity, providing evidence that lipogenesis can be independent of insulin control, but may depend on carbohydrate availability [81].

Other studies dealing with the effect of high fructose feeding on mitochondrial and peroxisomal $\beta$-oxidation found that fructose has been implicated in reducing PPAR $\alpha$ in rat hepatocytes. Eight weeks of a high fructose diet induced a decrease in $\operatorname{PPAR} \alpha$, which is a ligand activated nuclear hormone receptor responsible for inducing mitochondrial and peroxisomal $\beta$-oxidation [82]. Therefore, fructose might induce hepatic cellular lipid accumulation due to decreased lipid oxidation following reducing PPAR $\alpha$.

Of interest, lipid accumulation in fructose-fed rodents has been suggested to be through intestinal flora. Recently, it has been shown the dietary alteration of intestinal flora increased levels of plasma lipopolysaccharides (endotoxin). Fructose fed mice were found to produce endotoxinemia and fatty liver that could be prevented with antibiotic treatment [83], suggesting a bacterial origin of fructose induced fatty liver.

\section{Adiposity and fat storage in adipose tissue}

Indeed high fructose feeding has been found to cause an increase in adiposity. High dietary fructose intake and increasing body adiposity is clearly linked in both rats submitted to $57 \%$ dietary fructose $[69,84,85]$ and in mice consuming fructose containing soft drinks (HFCS, $15 \%, 61 \mathrm{Kcal} / 100 \mathrm{ml}, 52 \mathrm{~g} /$ day) [86]. The increased adipose tissue mass in 3 or 6 week-fructose fed rats has been attributed in part to decreased isoproterenol-stimulated lipolysis and to the increased antilipolytic action of insulin [69]. Lipogenesis in rats, however, is found to be shifted to the liver because fructose feeding: 1. activates lipogenic enzymes such as fatty acid synthase and malic enzyme in the liver but not in the adipose tissue $[72,87]$, and 2 . depresses conversion of glucose to lipids in adipose tissue $[13,87,88]$. Nevertheless, a recent study demonstrated that very long periods (6 months) on HFCS might increase adipose tissue fat in Sprague Dawley rats [89].

Similarly, intracellular lipid accumulation in the cytoplasm of muscle fibres has been demonstrated after several weeks of high sucrose diet, not a pure fructose diet, leading to insulin resistance [90].
Therefore, in animals a high fructose diet induces lipogenesis mainly in the liver or muscle fibers but not in the adipose tissue. However the increased adiposity in adipose tissue would most likely be due to decreased lipid mobilization. Various mechanisms were implicated. These results were induced with high doses of fructose either as dietary fructose or as drinks; and therefore, these effects in rodents could no be extrapolated to effects with physiologically significant amounts in humans.

\section{Acute studies in humans}

In an attempt to understand the mechanisms involved in fructose-induced hypertriglyceridemia and its contribution to de novo lipogenesis in an acute setting, in humans, the group of Frayn [91] used a high dose of fructose $0.75 \mathrm{~g} / \mathrm{Kg}$ body weight in a liquid breakfast of mixed macronutrients. [2H2] Palmitate and [U13 C] fructose or [U13 C] glucose were added to trace the handling of dietary fats and the fate of dietary sugars in the body. Compared with glucose, fructose consumed with the fat-containing liquid increased the 4-h appearance of the meal's fatty acid in VLDL. They found, however, that the large amount of fructose used led to impaired triacylglycerol clearance rather than contributing to de novo lipogenesis.

In addition, Parks and co-workers [7] aimed to determine the magnitude by which acute consumption of fructose in a morning bolus would further increase TG concentrations after the next meal. Six healthy subjects consumed carbohydrate boluses of sugar (85g each) in a random order followed by a standard lunch 4 hours later. Subjects consumed either a control test of glucose (100\%), a mixture of 50: 50 or 25:75 (wt:wt) glucose: fructose. The investigators demonstrated that post meal lipogenesis increased in proportion to fructose concentration in a beverage: from $7.8 \%$ for $100 \mathrm{~g}$ glucose beverage to $15.9 \%$ after a mixture of $50 \mathrm{~g}$ glucose: $50 \mathrm{~g}$ fructose and $16.9 \%$ after a mixture of $25 \mathrm{~g}$ glucose: $75 \mathrm{~g}$ fructose beverage. Body fat synthesis was measured immediately after the sweet drinks were consumed. This study concluded that fructose has an immediate acute lipogenic effect; with greater serum TG level in the morning, and after a subsequent meal, even if consumed as a small amount in a mixture of sugars. The small amount was either $50 \mathrm{~g}$ or $75 \mathrm{~g}$ taken with glucose in a beverage. However, it is misleading to suggest that the consumption of a specific food or food ingredient was the cause of obesity and the rise of Type 2 diabetes. Similar results with high fructose-sweetened beverages showed an immediate increase of acute 24-hour TG in obese men and women [92].

On the other hand, the fate of fructose may be its oxidation and not only TG accumulation. Using an oral 
fructose load of 0.5 or $1 \mathrm{~g} / \mathrm{Kg}$ (diluted in water), Delarue et al [93] reported that $56 \%$ or $59 \%$ of fructose load was oxidized over 6-h study. Again, a very high dose of fructose was used to examine this pathway.

The studies cited above used high amounts of fructose with or without labeled fructose to induce hypertriglyceridemia in an acute setting to evaluate underlying mechanisms. We can not draw negative conclusions about moderate amounts of fructose as the cause of obesity epidemic from these studies.

\section{Chronic studies in humans}

Swarbrick et al [94], evaluated the metabolic effect of 10 week consumption of fructose-sweetened beverages ( $25 \%$ of total carbohydrates). The authors demonstrated that the consumption of fructose-sweetened beverages increased postprandial TG and fasting apo B concentration. They suggested that long-term consumption of diets high in fructose could lead to an increased risk of cardiovascular diseases. Nevertheless, the conclusion was drawn after a study undertaken in only 7 overweight or obese postmenopausal women with special metabolism and a special type of adiposity. Limitations of this study are mainly due to the substantial variations of postprandial TG, (see Figure 2-A). The presented SEMs are great with expected high and overlapping SD values. Moreover, this study in one group consuming fructose sweetened beverages lacks comparison with another group consuming sucrose sweetened beverages.

Later, the same group [23] using a similar protocol, but in a group of overweight/obese subjects (16 men and 16 women), compared the effect of glucose to that

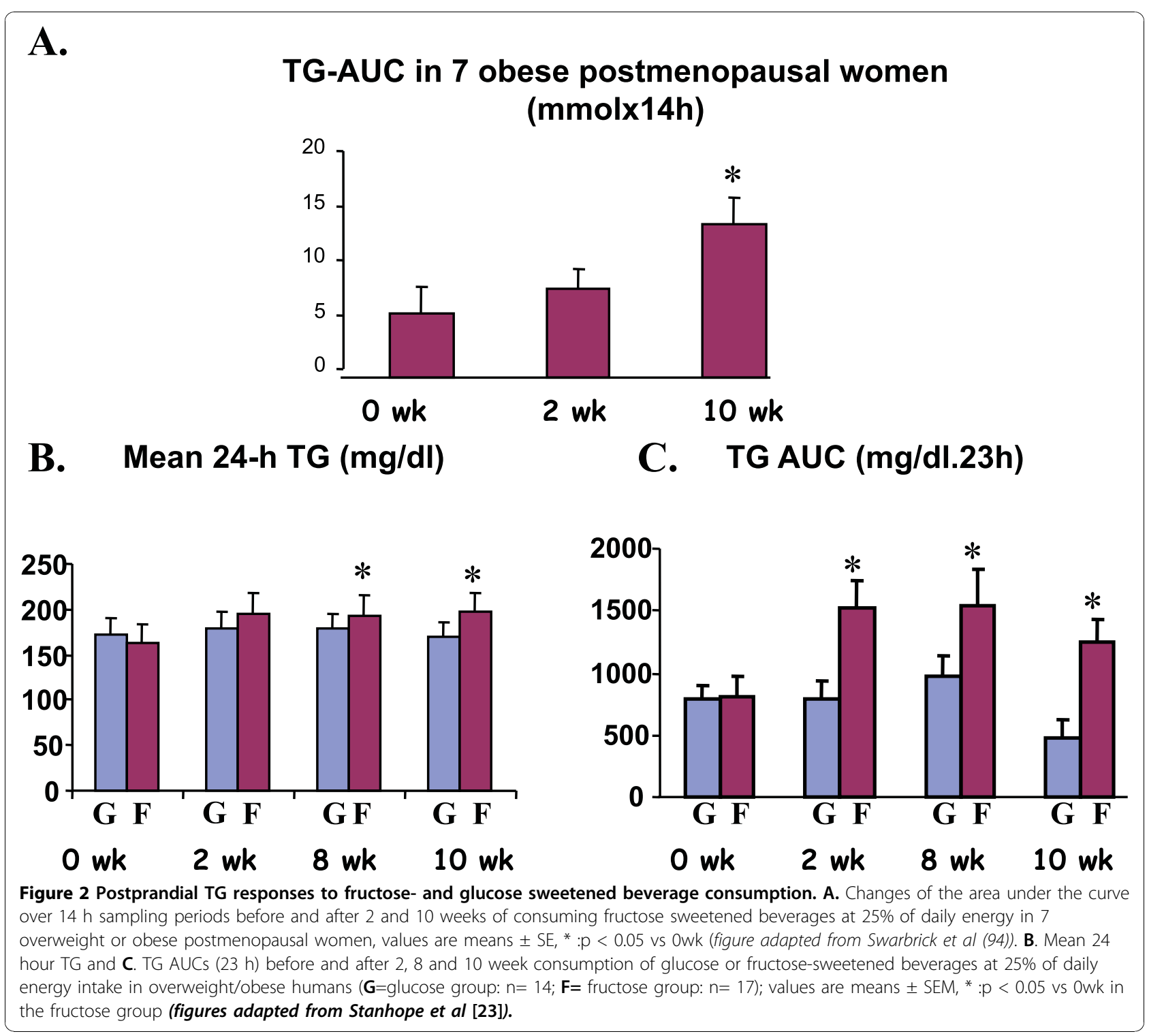


of fructose- sweetened beverages providing 25\% of energy requirements for 10 weeks in overweight and obese subjects on visceral adiposity, plasma lipids and insulin sensitivity. The carbohydrate intake of these subjects was 25\% from sweetened beverages and 30\% complex carbohydrates. This means that fructose or glucose represented half of the provided carbohydrates; as mentioned in the study: this amount was higher than $15.8 \%$ (the current estimate for the mean intake of total added sugars by Americans [95]). The authors evaluated the effect of the sweetened beverages with an ad libitum diet, meaning that subjects could eat as much as they want without any special recommendation or counseling concerning food intake. As expected both groups exhibited significant increase in body weight, fat mass, and waist circumference, without any difference between the two groups. The authors said that visceral adipose volume was significantly increased only in subjects consuming the fructose-sweetened beverages. However, it was not clear how total visceral adipose tissue was measured. The authors cited that they had done a CT scan at the umbilicus level. This means that this was in a one cross section at one level. Moreover, even by DEXA measurements (Dual energy X-ray absorptiometry) visceral or subcutaneous adipose tissue could not be estimated precisely. Therefore, it is misleading to say that in such a study visceral fat is increased by fructosesweetened beverages. On the other hand, it is not surprising that high amounts of fructose might induce postprandial hypertriglyceridemia as well as increase fasting LDL and apo B. The limitation of this study is the great variations in the SEM presented (figure $2 \mathrm{~B}$ and $2 \mathrm{C})$. In addition, while it is true that fructose consumption increased the 23-hour postprandial TG AUC as well as the mean $24 \mathrm{~h}$ TG compared to results before fructose consumption, there was no significant difference between glucose- and fructose-sweetened beverage consumptions (Figure2B and 2C).

Havel et al [92] demonstrated later that the increase in TG excursions during 24 hours (Area under curve) of fructose beverages depends mainly on the degree of insulin resistance of obese subjects.

Recently, Lê et al [96] found that a 7-day hypercaloric high-fructose diet (3.5 g fructose $/ \mathrm{kg} /$ day, $+35 \%$ energy intakes) increased ectopic lipid deposition in liver and muscle and fasting VLDL-TG as could be expected with these high amounts. The alteration in plasma lipids was more pronounced in a group of healthy offspring of patients with type 2 diabetes, who might be more susceptible to developing lipid alterations when subjected to high fructose intake. This is in agreement with the finding of the same group in 7 healthy men [22] demonstrating that four weeks of a high fructose diet containing $1.5 \mathrm{~g}$ fructose/kg body weight/day increased plasma
TG but without causing liver or muscle lipid deposition or insulin resistance in these healthy subjects.

One of the effects of fructose intake is a suppression of plasma free fatty acids, which suggests an inhibition of adipose tissue lipolysis [97]. While this has been confirmed in rats on isolated adipocytes [69], the same effect has been shown in healthy subjects after 7 days on a high fructose diet [98].

In humans, in acute as well as in chronic studies, high ( $>15 \%$ Energy, more than $50 \mathrm{~g} /$ day), fructose feeding has been found to elevate daylong serum triglycerides in healthy subjects ([17], [99-102]103), diabetic patients [104] and overweight/obese subjects [23,105]. Evidence exist that the elevated postprandial triglyceride levels as well as lipid deposition in liver and muscle depend on insulin resistant status of the subjects.

\section{Epidemiological Studies}

In a longitudinal study Fung et al [106] found that women who drink two or more servings of sweetened beverages per day may increase their risk of heart disease by 35 per cent. The study evaluated data from 88,520 women 34 to 59 years old participating in the Nurses' Health Study. The women were free of coronary heart disease or diabetes at the end of the study in 1980. Seven food-frequency questionnaires between 1980 and 2002 were used to evaluate dietary habits. While in this study subjects were put on all sweetened beverages. The authors accused fructose, since it had been the major sweetener in the sugar sweetened beverages. However, none of the observational data were able to establish causality.

While most studies have been conducted in adults, rare studies have been done in children.

Studying normal-weight and overweight 6-14 old Swiss children, Aeberli et al [4] aimed to determine whether LDL particle size is associated with dietary factors and especially with fructose intake. The authors used a cross-sectional, and not interventional, study in 74 children and dietary intakes were estimated by using two 24-h recalls and a one-day dietary record. Although there were no significant differences in total fructose intake, the authors concluded that after adjusting the results for adiposity, fructose intake was a significant predictor of LDL particle size, which was significantly smaller in the overweight children than in the normal weight ones. However, upon further examination, these values (Figure 3), the LDL particle size, while described as statistically different, could not have significant clinical impact with only a $1.7 \%$ reduction between the two groups with overlapping of values (great SD). This study gave quite a negative image of fructose and reopened the debate on whether fructose consumption itself was a health risk. Again it must be noted that this was a 


\section{LDL-particle size in normal and overweight Swiss Children (6-14 years old) \\ $\operatorname{mean} \pm$ SD}

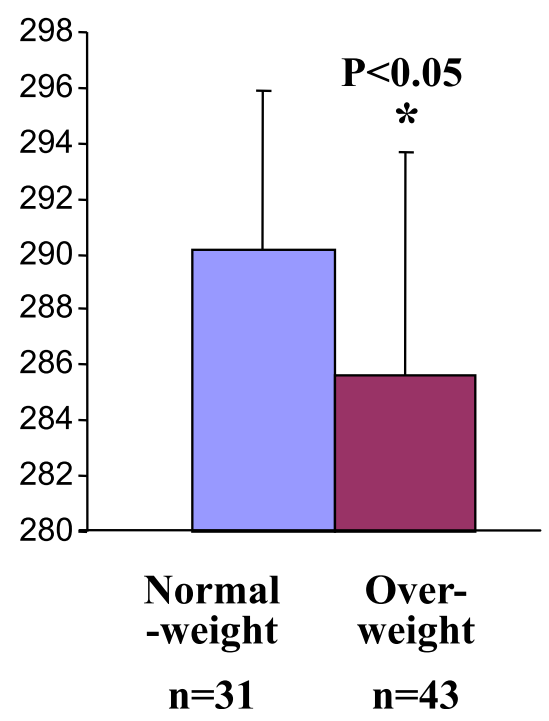

Figure 3 LDL particle size in 6 to 14 years old Swiss children, values are means \pm SD, (Figure adapted from Aeberli et al [4].

cross sectional study and that the main outcome is based on dietary recalls or dietary records. Dietary recalls, even when validated, can not give precise results, particularly in children, because their ability to record or remember their diet is limited $[107,108]$. In this study there was no association between fructose consumption and HDL, LDL, total cholesterol or triacylglycerol. The study failed to demonstrate an increase in total fructose intake in the overweight children. However, the authors cited that overweight children consumed significantly less fructose, as a percentage of total fructose, from fruits and vegetables but more fructose, also as a percentage of total fructose, from sweetened drinks and sweets. This is some what misleading, because the absolute amounts of fructose intake from fruits and vegetables or from sweet drinks did not differ significantly between the two groups. In addition, the correlation between LDL size and total fructose intake was poor, $\beta=-0.245$. This poor correlation, however, could not confirm a causal relationship. In a debate entitled "Fructose: Sweet or Bitter for Diabetes" that took place during the 26th Symposium on Diabetes and Nutrition Study Group (DNSG, 2008, Varna, Bulgaria) of the EASD, the author (Dr Isabelle Aeberli) admitted that the problem with fructose is due mainly to the amount utilized and not to fructose itself. Moreover, the generation of small triacylglycerol rich lipoprotein particles, such as generated by fructose, does not itself seem to be a sufficient condition for atherogenesis [109].

\section{Meta analysis}

In a recent meta-analysis Livesey and Taylor [40] examined 60 studies looking at the link between fructose intake on fasting plasma TG and 25 studies dealing with the effect of fructose on postprandial plasma TG in humans. This meta-analysis included different types of subjects: healthy, with impaired fasting glucose, impaired glucose tolerance, type 2 diabetes, subjects with elevated risk of coronary heart disease, and subjects with any form of hyperlipidemia. The authors found that fructose intake $<50 \mathrm{~g} / \mathrm{d}$ had no significant effect on triacylglycerol post- prandially and $\leq 100 \mathrm{~g} / \mathrm{d}$ had no significant effect on fasting levels but was associated with increased postprandial TG excursions. Consumption of $50 \mathrm{~g}$ fructose per day for up to 2 years is without effect on fasting plasma triacylglycerol in healthy individuals [110]. At a daily fructose dose $>100 \mathrm{~g}$, the effect on fasting triacylglycerol depended on whether sucrose or starch was being exchanged with fructose. This effect was dose dependent, and was lower with increasing the duration of treatment. Different health types and sources of bias were examined showing no significant departure from a general trend.

In another meta-analysis, a Canadian group evaluated the differential effects of isocaloric exchange of fructose for other carbohydrates on triglycerides in peoples with diabetes [111]. They selected 14 papers meeting their criteria out of a total of 725 papers. There was no significant effect of the isocaloic exchange of fructose for $\mathrm{CHO}$ on TG with strong heterogeneity. In a further analysis separating patients with type 2 diabetes from those with type 1 diabetes, fructose was found to increase triglycerides in type-2 but not type-1 diabetes. This effect could be detected when high doses of fructose was taken $(>65 \mathrm{~g} / \mathrm{d})$ during short- term $(\leq 4$ weeks) and when fructose substituted starch $[112,113]$ but not sucrose [114-116]. Moderate fructose consumption $(<50 \mathrm{~g} / \mathrm{d}$, or $\sim 10 \%$ of metabolizable energy intake) has previously been considered acceptable in diabetics $[109,117,118]$.

Therefore, $<50 \mathrm{~g} /$ day added fructose by day has no deleterious effect on both fasting and postprandial triglycerides.

\section{Fructose and insulin resistance}

\section{Evidence from experimental studies in animals}

There is much evidence in animal models supporting the notion that fructose when consumed in high amounts contributes to hepatic and peripheral insulin resistance $[70,71,119,120]$. In rats fed a fructose- rich diet Thorburn et al [120], using the hyperinsulinemic euglycemic clamp method, demonstrated lower insulin 
stimulated glucose uptake in hindlimb muscles and adipose tissues than in rats fed a dextrose rich diet. A decrease in skeletal and hepatic insulin receptor number, determined by an in situ autoradiography technique, as well as a decrease in their gene expression was found by $66 \%$ fructose feeding for 2 weeks in rats [121]. Moreover, decreased insulin-induced insulin receptor phosphorylation was demonstrated in the liver of fructose fed rats[122] A 57\% fructose diet induced, similarly, a decrease in insulin stimulated glucose incorporation into lipids but increased the antilipolytic action of insulin in isolated adipocytes of normal rats $[13,69]$.

Three weeks of a $10 \%$ fructose-rich diet [123] induced adaptive changes in islets of rats: decreased $\beta$-cell mass with increasing apoptotic cells, increased glucoseinduced insulin release and islet glucose metabolism, increased glucokinase, but not hexokinase activity. These modifications resulted in an increase of insulin release in spite of marked $\beta$-cell mass reduction leading to hyper insulinemia, impaired glucose tolerance and insulin resistance.

Here again, the high fructose fed rats used as a model of insulin resistance to evaluate the islet adaptive changes in such situations (peoples at risk of developing type 2 diabetes). Recently, the group of Havel [124] has demonstrated that 4 months of sustained fructose consumption (20\% of energy) accelerate the onset of type 2 diabetes in a model of pylogenic obese type 2 diabetic rats. The presence of an antioxidant with insulin sensitizing activity ameliorates the effect of fructose by improving glucose homeostasis, which is likely due to preserving $\beta$-cell function.

Moreover, fructose-fed rats demonstrated a defect in neural insulin signaling pathway in the brain. Decreased insulin stimulated-tyrosine phosphorylation of insulin receptors and insulin receptor substrate 1 (IRS-1) were demonstrated in the fructose-fed hamsters [125]. Also insulin-mediated phosphorylation of residues necessary for activation of another key effector of insulin signalling was markedly decreased.

Nevertheless, high fructose-fed rat model is often used in many studies as a dietary model of insulin resistance $[15,126,127]$. In rodents, therefore, there is no doubt that high-fructose feeding cause insulin resistance.

\section{Acute Studies in Humans}

In humans, hardly any evidence exists to confirm directly the negative effects of fructose on insulin sensitivity. Fructose has been considered as a therapeutic tool in the diet of diabetic patients due to its low glycemic index [128] and because it's initial metabolic steps do not need insulin [79]. It elicits an increase in energy expenditure that has been suggested to be beneficial for obese subjects with or without diabetes $[97,129]$. The effect of fructose infusion on hepatic insulin sensitivity in conditions of moderate hyperglycaemia has been studied during hyperglycaemic clamp study with or without infusion of $16.7 \mu \mathrm{mol} / \mathrm{kg} / \mathrm{min}$ fructose [130]. The acute fructose infusion induced both extra hepatic and hepatic insulin resistance, which has been suggested to be secondary to an increased intrahepatic glucose 6-phosphate synthesis. These results raise questions as to whether ingested fructose as part of the diet may have the same effects.

\section{Chronic studies in humans}

Consuming an extra $1000 \mathrm{Kcal}$ as fructose, which is a high amount, for one week induced a reduction in both insulin binding and insulin sensitivity when compared to effects after the same amount of glucose in young healthy subjects [131]. In a special case, the presence of fructose as the unique source of carbohydrate in a very low calorie diet $(600 \mathrm{Kcal})$ postponed by two weeks the expected amelioration of a low calorie diet for plasma glucose and insulin levels as well as insulin binding [132].

Moderate fructose intake (1/3 carbohydrate intake), however, in healthy subjects for 2 weeks has no deleterious effect on insulin sensitivity compared to the same amount of sucrose [133,134].

In healthy subjects, consuming up to $1.5 \mathrm{~g}$ fructose $/ \mathrm{kg}$ body weight per day for 4 weeks increased plasma triglycerides but without inducing insulin resistance [135]. The authors of the latter study were able, however, to detect early molecular alterations in only two skeletal muscle genes. They suggested, therefore, that these alterations could induce later whole body insulin resistance [135]. The same group showed that fructose overfeeding (3.5 g fructose/kg fat-free mass/day, again a high dose) for 6 days produces hepatic insulin resistance in men, whereas these effects are markedly blunted in healthy young men[136].

In diabetic subjects, other chronic studies could not detect any deleterious effects of moderate fructose intakes: $30 \mathrm{~g}$ fructose/day compared to starch as a part of $1400-1600 \mathrm{Kcal}$ for 8 weeks [112], or one year [137] or $60 \mathrm{~g}$ fructose/day for 12 weeks, [138] or 6 months [139].

Using high amount of fructose, however, as fructosesweetened beverages at $25 \%$ of energy requirements for 10 weeks, led to an increase in fasting plasma glucose and insulin levels and decreased insulin sensitivity compared to the same amount of glucose sweetened beverages [23].

\section{Epidemiological studies}

In a prospective large cross-sectional study -Nurses Healthy Study I and II- an association was found 
between high intake of fructose and the high C-peptide concentrations [140]. Due to this association, the authors suggested that fructose intake may play a role in the development of insulin resistance and type 2 diabetes. However, causal relationship could not be identified from this study design.

In a longitudinal study, Janket et al [141] evaluated the relationship between risk of type 2 diabetes and intakes of total caloric sweeteners, sucrose, fructose, glucose and lactose in a cohort of 38,480 female health professionals. Neither fructose, glucose nor sucrose was related to the risk of developing type 2 diabetes. Therefore, no difference could be detected between the different sugars.

While some investigators are able to detect deleterious effects with high doses or could not detect with moderate doses, others found beneficial effects. Koivisto et al [113] demonstrated that the substitution of moderate amounts of fructose (45-65 g/day: $20 \%$ of carbohydrate calories) for complex carbohydrates for 4 weeks improves insulin sensitivity in type 2 diabetic patients. Similarly Reiser et al [102] found that patients adapted to $20 \%$ of energy as fructose for 5 weeks had improved plasma glucose responses to a glucose charge compared to a group adapted to starch diet. In a group of children with diabetes $1 \mathrm{~g}$ fructose $/ \mathrm{kg} /$ day ( $30 \mathrm{~g} /$ day maximum) with guar gum for three weeks was found to decrease HBA1c but with increased glucoseuria [142].

In small doses, however, dietary fructose appears to be beneficial in enhancing glucose tolerance $[143,144]$. The addition of small doses of fructose to a glucose meal can enhance hepatic glucose disposal. Moreover, the addition of small amounts of fructose to orally ingested glucose increases hepatic glycogen synthesis and reduces glycemic responses in subjects with type 2 diabetes [145]. This effect was found to be due to a rise in Fructose-1-P which has an important indirect effect on hepatic glucose metabolism by modulating glucokinase activity which is a key regulatory enzyme required for the formation of glucose -6-P. Glucokinase also is involved in the inhibition of hepatic glucose release by portal hyperglycemia [146]. Fructose-1-P, at low levels antagonizes a glucokinase regulatory protein, enhancing, then, glucokinase activity. Stimulation of hepatic glycogen synthesis by this mechanism may be of potential therapeutic value. However, high doses could be deleterious.

Recently, a meta-analysis [40] demonstrated that fructose intakes from 0 to $\geq 90 \mathrm{~g} / \mathrm{d}$ have a beneficial effect on HbA1c. This meta-analysis was done on a group of studies in healthy, glucose intolerant and type-2 diabetes. The authors, however, are aware that 50 to $100 \mathrm{~g}$ is a high fructose intake that could affect postprandial triglycerides. Whether a lowering or maintaining of low
HbA1c with these doses of fructose would persist is unknown. We could conclude that moderate fructose consumption $(<50 \mathrm{~g} / \mathrm{d}$, or $>10 \% \mathrm{ME})$ appears acceptable and potentially beneficial.

\section{Fructose ingestion acutely elevates blood pressure}

Brown and co-workers [147] showed recently that the acute ingestion of both glucose and fructose drinks (60 g) brings about specific hemodynamic responses. Fructose, in particular elicits an increase in blood pressure that could be probably mediated by an increase in cardiac output without compensatory peripheral vasodilatation.

While fructose-induced hypertension is well demonstrated in rodents via various mechanisms [148], in humans long-term demonstration failed. In the Nurses' Health Study, fructose intake was not associated to the risk for developing hypertension [149]. Moreover, recently [136] in a chronic study using high fructose amount of $1.5 \mathrm{~g} / \mathrm{kg}$ body weight by day for 4 weeks, there was no significant change in mean blood pressure at the end of four week-fructose diets. There is no existing evidence for the relation between fructose and hypertension in humans.

\section{Fructose consumption and the risk of gout in humans}

Prospective data has suggested that consumption of sugar sweetened soft drinks and fructose is strongly associated with an increased risk of gout in men [150]. They concluded that other contributors to fructose intake such as total fruit juice or fructose rich fruits (apples and oranges) were also associated with high risk of gout. In these studies information was provided on intake of soft drinks and fructose through validated food frequency questionnaires. These studies could not confirm a cause and effect relationship. When comparing 5 weeks of fructose consumption to 5 weeks of that of starch (20\% of energy), serum uric acid increased with fructose intake [102]. The authors compared a simple sugar to a complex one; therefore, these findings could be simply due to the effect of a refined sugar. This hypothesis is likely, because when comparing $24 \%$ of carbohydrates consumed as fructose to that amount consumed as sucrose, no alteration in uric acid level was detected [151]. On the other-hand when a high fructose amount $250-290 \mathrm{~g} / \mathrm{d}$ was taken for 12 days an increase in both plasma and urinary uric acid was found [152]. Others believe that fructose-induced hyperuricaemia occurs mainly in gouty patients [153].

\section{Fructose and Exercise}

Substrate utilization during exercise with glucose and glucose plus fructose ingestion has been an important 
focus of study. In contrast to glucose during exercise, exogenous fructose has delayed the rate of intestinal absorption [154], lowering the rate of oxidation during exercise $[155,156]$ possibly as a result of its slower absorption rate and the necessity for its conversion to glucose by the liver before oxidation [156]. The combination of fructose and glucose, however, is well absorbed during exercise [157] and may facilitate a higher oxidation than either of the two sugars ingested separately [158]. The ingestion of glucose alone and glucose plus fructose delays exhaustion at $90 \%$ peak power by 25 and $40 \%$ after 90 minutes of moderateintensity exercise [159]. While pre-exercise and exercise ingestion of glucose and fructose are of equal values in delaying exhaustion, ingestion of fructose before and during the exercise provide a more constant supply of available glucose to the working muscle [160].

\section{Other beneficial effects}

Dietary fructose (20\% of the calories from fructose) enhances mineral balance [161]. Another effect is that the intake of $250 \mathrm{ml}$ of a drink rich in fructose after alcohol consumption will decrease the plasma alcohol levels by $10 \%$ [162].

\section{Conclusions}

Certainly high fructose consumption can induce insulin resistance, impaired glucose tolerance, hyperinsulinemia, hypertriglyceridemia, and hypertension in animal models. There is no evidence for similar effects in humans at realistic consumption patterns. Although there are existing data on the metabolic and endocrine effects of dietary fructose that suggest that increased consumption of fructose may be detrimental in terms of body weight and adiposity and the metabolic indexes associated with the insulin resistance syndrome, much more research is needed to fully understand the metabolic effect of dietary fructose in humans. Despite the epidemiological parallel between the marked increase of obesity and fructose consumption, there is no direct evidence linking obesity to the consumption of physiological amounts of fructose in humans $(\leq 100 \mathrm{~g} /$ day $)$. A moderate dose ( $\leq 50 \mathrm{~g} /$ day) of added fructose has no deleterious effect on fasting and postprandial triglycerides, glucose control and insulin resistance. There is no existing evidence for a relation between moderate fructose consumption and hypertension. Fructose may induce hyperuricaemia, but mainly in patients with gout.

Beneficial effects of moderate amounts of fructose have also been demonstrated: 1. Fructose seems to decrease appetite when taken in a solution or puddings before a meal, 2 . It seems to lower plasma glucose responses to orally ingested glucose via stimulation of hepatic glycogen, when added to the glucose challenge, 3 . While pre-exercise and exercise ingestion of glucose and fructose are of equal values in delaying exhaustion, ingestion of fructose before and during the exercise provide a more constant supply of available glucose to the working muscle.

Two new reviews were published during the revision of this manuscript that strengthen our conclusions: The first is an evidence-based review [163] indicating that fructose does not cause biologically relevant changes in TG or body weight when consumed at levels approaching 95th percentile estimates of intake. This review is based on recent guidance developed by the US Food and Drug Administration (FDA) [164]. The second review by Tappy and Lê [37] concluded that: 1) there is no unequivocal evidence that fructose intake at moderate doses is directly related with adverse events in man; 2) there is no direct evidence for more serious metabolic consequences of high fructose corn syrup versus sucrose consumption.

The implications of any balance of effects of fructose on different aspects of metabolism in terms of possible risk to health would need to be ascertained using more direct long-term intervention studies.

\section{Acknowledgements}

The author thanks Nazila Senehipour, Marie Déniel (Lr Beva Nutrition, France) for their help in the collection of recent literature and their thoughtful assistance. Thanks also for Henry Hooton (INSERM U872, team 7) for critical English revision of the manuscript.

The authors' responsibilities were as follows: SR was involved with the conceptualization of the manuscript, review of the literature, and drafting and editing of the document. This work has been supported by grants from the French National Institute of Health and Medical Research (INSERM) and from Pierre and Marie Curie University, Paris 6

\section{Author details}

'INSERM, U872, équipe 7 Nutriomique, Université Pierre et Marie Curie-Paris 6, Centre de Recherche des Cordeliers, UMR S 872, Paris, 75006 France. ${ }^{2}$ Centre de Recherche Nutrition Humaine, Ile de France, Assistance PubliqueHôpitaux de Paris, Hôpital Pitié-Salpêtrière, Département de Nutrition et d'Endocrinologie, Paris, 75013 France.

\section{Competing interests}

The author declares that they have no competing interests.

Received: 12 February 2010 Accepted: 4 November 2010 Published: 4 November 2010

\section{References}

1. Miller A, Adeli K: Title Dietary fructose and the metabolic syndrome. Current Opinion in Gastroenterology 2008, 24:204-209.

2. Bray GA, Nielsen SJ, Popkin BM: Consumption of high-fructose corn syrup in beverages may play a role in the epidemic of obesity. Am J Clin Nutr 2004, 79:537-543.

3. Bray G: How bad is fructose? Am J Clin Nutr 2007, 86:895-896

4. Aeberli I, Zimmermann MB, Molinari $L$, et al: Fructose intake is a predictor of LDL particle size in overweight schoolchildren. Am J Clin Nutr 2007 86:1174-1178.

5. Nakagawa T, Hu H, Zharikov S, et al: A causal role for uric acid in fructoseinduced metabolic syndrome. Am J Physiol Renal Physiol 2006, 290: F625-631. 
6. Vos M, Kimmons J, Gillespie C, Welsh J, Blanck H: Dietary fructose consumption among US children and adults: the Third National Health and Nutrition Examination Survey. Medscape J Med 2008, 10(7):160.

7. Parks EJ, Skokan LE, Timlin MT, Dingfelder CS: Dietary Sugars Stimulate Fatty Acid Synthesis in Adults. J Nutr 2008, 138:1039-1046.

8. Wolfgang MJ, Cha SH, Sidhaye A, et al: Regulation of hypothalamic malonyl-CoA by central glucose and leptin. Proc Natl Acad Sci USA 2007, 104:19285-90.

9. Miller CC, Martin RJ, Whitney ML, Edwards GL: Intracerebroventricular injection of fructose stimulates feeding in rats. Nutr Neurosci 2002 5:359-62.

10. Cha SH, Wolfgang M, Tokutake $Y$, Chohnan S, Lane MD: Differential effects of central fructose and glucose on hypothalamic malonyl-CoA and food intake. Proc Natl Acad Sci USA 2008, 105:1-5, 1687.

11. White JS: Straight talk about high-fructose corn syrup: what it is and what it ain't. Am J Clin Nutr 2008, 88:1716S-1721S.

12. Shapiro A, Mu W, Roncal C, Cheng KY, Johnson RJ, Scarpace PJ: Fructoseinduced leptin resistance exacerbates weight gain in response to subsequent high-fat feeding. Am J Physiol Regul Integr Comp Physiol 2008, 295:R1370-5.

13. Luo J, Rizkalla SW, Lerer-Metzger $M$, et al: A fructose-rich diet decreases insulin-stimulated glucose incorporation into lipids but not glucose transport in adipocytes of normal and diabetic rats. J Nutr 1995, 125:164-171

14. Luo J, Rizkalla S, Alamowitch C, et al: Neither dietary fructose, dextrose nor starch modifies in vitro glycerol release by adipocytes from streptozotocin-diabetic rats. J Nutr 1992, 122:2361-2366.

15. Axelsen LN, Pedersen HD, Petersen JS, Holstein-Rathlou NH, Kjolbye AL: Metabolic and cardiac changes in high cholesterol-fructose-fed rats. Pharmacol Toxicol Methods 2010, 61(3):292-6.

16. Young LR, Nestle M: The Contribution of Expanding Portion Sizes to the US Obesity Epidemic. Am J Public Health 2002, 92:246-249.

17. Teff KL, Elliott SS, Tschop M, et al: Dietary Fructose Reduces Circulating Insulin and Leptin, Attenuates Postprandial Suppression of Ghrelin, and Increases Triglycerides in Women. J Clin Endocrinol Metab 2004, 89:2963-2972.

18. Soenen S, Westerterp-Plantenga MS: No differences in satiety or energy intake after high-fructose corn syrup, sucrose, or milk preloads. Am J Clin Nutr 2007, 86:1586-1594.

19. Akhavan T, Anderson GH: Effects of glucose-to-fructose ratios in solutions on subjective satiety, food intake, and satiety hormones in young men. Am J Clin Nutr 2007, 86:1354-1363.

20. Stanhope KL, Griffen SC, Bair BR, Swarbrick MM, Keim NL, Havel PJ: Twentyfour-hour endocrine and metabolic profiles following consumption of high-fructose corn syrup-, sucrose-, fructose-, and glucose-sweetened beverages with meals. Am J Clin Nutr 2008, 87:1194-1203.

21. Melanson KJ, Zukley L, Lowndes J, Nguyen V, Angelopoulos TJ, Rippe JM: Effects of high-fructose corn syrup and sucrose consumption on circulating glucose, insulin, leptin, and ghrelin and on appetite in normal-weight women. Nutrition 2007, 23:103-112.

22. Lê K, Faeh D, Stettler $R$, et al: A 4-wk high-fructose diet alters lipid metabolism without affecting insulin sensitivity or ectopic lipids in healthy humans. Am J Clin Nutr 2006, 84(6):1374-9.

23. Stanhope KL, Schwarz JM, Keim NL, et al: Consuming fructose-sweetened, not glucose-sweetened, beverages increases visceral adiposity and lipids and decreases insulin sensitivity in overweight/obese humans. J Clin Invest 2009, 119:1322-34

24. James J, Thomas P, Cavan D, Kerr D: Preventing childhood obesity by reducing consumption of carbonated drinks: cluster randomised controlled trial. Bmj 2004, 328:1237.

25. Bray G: Fructose: should we worry? Int J Obes (Lond) 2008, 32(Suppl 7) S127-31.

26. Forshee $R$, Storey $M$, Allison $D$, et al: A critical examination of the evidence relating high fructose corn syrup and weight gain. Crit Rev Food Sci Nutr 2007, 47(6):561-82.

27. Forshee RA, Anderson PA, Storey ML: The role of beverage consumption physical activity, sedentary behavior, and demographics on body mass index of adolescents. Int J Food Sci Nutr 2004, 55:463-78.

28. Forshee RA, Storey ML: Total beverage consumption and beverage choices among children and adolescents. Int J Food Sci Nutr 2003, 54:297-307.
29. Giammattei J, Blix G, Marshak HH, Wollitzer AO, Pettitt DJ: Television watching and soft drink consumption: associations with obesity in 11to 13-year-old schoolchildren. Arch Pediatr Adolesc Med 2003, 157:882-6.

30. Nicklas TA, Yang SJ, Baranowski T, Zakeri I, Berenson G: Eating patterns and obesity in children. The Bogalusa Heart Study. Am J Prev Med 2003, 25:9-16.

31. Field AE, Austin SB, Gillman MW, Rosner B, Rockett HR, Colditz GA: Snack food intake does not predict weight change among children and adolescents. Int J Obes Relat Metab Disord 2004, 28:1210-6.

32. Berkey CS, Rockett HR, Field AE, Gillman MW, Colditz GA: Sugar-added beverages and adolescent weight change. Obes Res 2004, 12:778-88

33. Newby PK, Peterson KE, Berkey CS, Leppert J, Willett WC, Colditz GA: Beverage consumption is not associated with changes in weight and body mass index among low-income preschool children in North Dakota. J Am Diet Assoc 2004, 104:1086-94.

34. Mrdjenovic G, Levitsky DA: Nutritional and energetic consequences of sweetened drink consumption in 6- to 13-year-old children. J Pediatr 2003, 142:604-10.

35. Forshee RA, Anderson PA, Storey ML: Sugar-sweetened beverages and body mass index in children and adolescents: a meta-analysis. Am J Clin Nutr 2008, 87:1662-71.

36. Vartanian LR, Schwartz MB, Brownell KD: Effects of soft drink consumption on nutrition and health: a systematic review and meta-analysis. Am J Public Health 2007, 97:667-75

37. Tappy L, Le KA: Metabolic effects of fructose and the worldwide increase in obesity. Physiol Rev 2010, 90:23-46.

38. Melanson KJ, Angelopoulos TJ, Nguyen V, Zukley L, Lowndes J, Rippe JM: High-fructose corn syrup, energy intake, and appetite regulation. Am J Clin Nutr 2008, 88:1738S-1744.

39. Tordoff MG, Alleva AM: Effect of drinking soda sweetened with aspartame or high-fructose corn syrup on food intake and body weight. Am J Clin Nutr 1990, 51:963-9.

40. Livesey G, Taylor R: Fructose consumption and consequences for glycation, plasma triacylglycerol, and body weight: meta-analyses and meta-regression models of intervention studies. Am J Clin Nutr 2008, 88:1419-1437.

41. Rodin J, Reed D, Jamner L: Metabolic effects of fructose and glucose: implications for food intake. Am J Clin Nutr 1988, 47:683-9.

42. Rodin J: Comparative effects of fructose, aspartame, glucose, and water preloads on calorie and macronutrient intake. Am J Clin Nutr 1990, 51:428-435.

43. Rodin J: Effects of pure sugar vs. mixed starch fructose loads on food intake. Appetite 1991, 17:213-9.

44. Hoekstra $\mathrm{JH}$, van den Aker $\mathrm{JH}$ : Facilitating effect of amino acids on fructose and sorbitol absorption in children. J Pediatr Gastroenterol Nutr 1996, 23(2):118-124.

45. Rumessen JJ, Gudmand-Hoyer E: Absorption capacity of fructose in healthy adults. Comparison with sucrose and its constituent monosaccharides. Gut 1986, 27:1161-1168.

46. Hu FB, Malik VS: Sugar-sweetened beverages and risk of obesity and type 2 diabetes: epidemiologic evidence. Physiol Behav 2010, 100:47-54.

47. Jenkins DJ, Kendall CW, Marchie A, Augustin LS: Too much sugar, too much carbohydrate, or just too much? Am J Clin Nutr 2004, 79:711-2.

48. Anderson JW, Randles KM, Kendall CWC, Jenkins DJA: Carbohydrate and Fiber Recommendations for Individuals with Diabetes: A Quantitative Assessment and Meta-Analysis of the Evidence. J Am Coll Nutr 2004, 23:5-17.

49. Clement $\mathrm{K}$, Vaisse $\mathrm{C}$, Lahlou $\mathrm{N}$, et al: A mutation in the human leptin receptor gene causes obesity and pituitary dysfunction. Nature 1998, 392:398-401.

50. Dubern B, Lubrano-Berthelier C, Mencarelli M, et al: Mutational analysis of the pro-opiomelanocortin gene in French obese children led to the identification of a novel deleterious heterozygous mutation located in the alpha-melanocyte stimulating hormone domain. Pediatr Res 2008, 63.211-6.

51. Willer CJ, Speliotes EK, Loos RJ, et al: Six new loci associated with body mass index highlight a neuronal influence on body weight regulation. Nat Genet 2009, 41:25-34.

52. Singh AS, Chin APMJ, Brug J, van Mechelen W: Dutch obesity intervention in teenagers: effectiveness of a school-based program on body composition and behavior. Arch Pediatr Adolesc Med 2009, 163:309-17. 
53. Muckelbauer R, Libuda L, Clausen K, Toschke AM, Reinehr T, Kersting M: Promotion and provision of drinking water in schools for overweight prevention: randomized, controlled cluster trial. Pediatrics 2009, 123: e661-7.

54. Epstein LH, Robinson JL, Temple $J$, Roemmich JN, Marusewski AL, Nadbrzuch RL: Variety influences habituation of motivated behavior for food and energy intake in children. Am J Clin Nutr 2009, 89:746-54.

55. Greenwood JJJ, Stanford JB: Preventing or Improving Obesity by Addressing Specific Eating Patterns. J Am Board Fam Med 2008, 21:135-140.

56. Young L, Nestle M: Portion sizes and obesity: responses of fast-food companies. J Public Health Policy 2007, 28:238-48.

57. Rutledge A, Adeli K: Fructose and the metabolic syndrome: pathophysiology and molecular mechanisms. Nutr Rev 2007, 65(6 Pt 2): S13-23, 2007.

58. Corpe CP, Burant CF, Hoekstra JH: Intestinal fructose absorption: clinical and molecular aspects. J Pediatr Gastroenterol Nutr 1999, 28:364-74.

59. Havel P: Dietary Fructose: Implications for Dysregulation of Energy Homeostasis and Lipid/Carbohydrate Metabolism. Nutrition Reviews 2005 63:133-157.

60. Cortez-Pinto H, Chatham J, Chacko VP, Arnold C, Rashid A, Diehl AM: Alterations in liver ATP homeostasis in human nonalcoholic steatohepatitis: a pilot study. Jama 1999, 282:1659-64.

61. Björkman O, Gunnarson R, Hagström E, Felig P, Wahren J: Splanchnic and renal exchange of infused fructose in insulin-deficient type 1 diabetic patients and healthy controls. J Clin Invest 1989, 83:52-59.

62. Bode C, Durr HK, Bode JC: Effect of fructose feeding on the activity of enzymes of glycolysis, gluconeogenesis, and the pentose phosphate shunt in the liver and jejunal mucosa of rats. Horm Metab Res 1981, 13:379-83

63. Topping DL, Mayes PA: The immediate effects of insulin and fructose on the metabolism of the perfused liver. Changes in lipoprotein secretion, fatty acid oxidation and esterification, lipogenesis and carbohydrate metabolism. Biochem J 1972, 126:295-311.

64. Van den Berghe G: Metabolic effects of fructose in the liver. Curr Top Cell Regul 1978, 13:97-135.

65. Waddell M, Fallon HJ: The effect of high-carbohydrate diets on liver triglyceride formation in the rat. J Clin Invest 1973, 52:2725-31.

66. Jeppesen J, Chen Y, Zhou M, Schaaf P, Coulston A, Reaven G: Postprandial triglyceride and retinyl ester responses to oral fat: effects of fructose. Am J Clin Nutr 1995, 61:787-791.

67. Haidari M, Leung N, Mahbub F, et al: Fasting and postprandial overproduction of intestinally derived lipoproteins in an animal model of insulin resistance. Evidence that chronic fructose feeding in the hamster is accompanied by enhanced intestinal de novo lipogenesis and ApoB48-containing lipoprotein overproduction. J Biol Chem 2002, 277:31646-55.

68. Lewis GF, Uffelman K, Naples M, Szeto L, Haidari M, Adeli K: Intestinal lipoprotein overproduction, a newly recognized component of insulin resistance, is ameliorated by the insulin sensitizer rosiglitazone: studies in the fructose-fed Syrian golden hamster. Endocrinology 2005, 146:247-55.

69. Rizkalla SW, Luo J, Guilhem I, et al: Comparative effects of 6 weeks fructose, dextrose and starch feeding on fat-cell lipolysis in normal rats : effects of isoproterenol, theophylline and insulin. Molecular and Cellular Biochemistry 1992, 109:127-132.

70. Rizkalla SW, Boillot J, Tricottet V, et al: Effects of chronic dietary fructose on glomerular basement membrane thickness and on glycemic and lipid control in normal rats. Effect of copper supplementation. $\mathrm{Br} J \mathrm{Nutr}$ 1993, 70:199-209.

71. Blakely SR, Hallfrisch J, Reiser S, Prather ES: Long-term effects of moderate fructose feeding on glucose tolerance parameters in rats. J Nutr 1981 111:307-314.

72. Blakely SR, Hallfrisch J, Reiser S, Prather ES: Long-term effects of moderate fructose feeding on lipogenic parameters on Wistar rats. Nutr Rep Int 1982, 25:675-685.

73. Elliott SS, Keim NL, Stern JS, Teff K, Havel PJ: Fructose, weight gain, and the insulin resistance syndrome. Am J Clin Nutr 2002, 76:911-922.

74. Pereira JN, Jangaard NO: Different rate of glucose and fructose metabolism in rat liver tissue in vitro. Metabolism 1971, 20:392-400.
75. Bar-On H, Stein Y: Effect of glucose and fructose administration on lipid metabolism in the rat. J Nutr 1968, 94:95-105

76. Baker N, Garfinkel AS, Schotz MC: Hepatic triglyceride secretion in relation to lipogenesis and free fatty acid mobilization in fasted and glucoserefed rats. J Lipid Res 1968, 9:1-7.

77. Butcher RW: The role of cyclic AMP in the actions of some lipolytic and anti-lipolytic agents. Horm Metab Res 1970, 2(Suppl 2):5-10.

78. Reaven GM, Lerner RL, Stern MP, Farquhar JW: Role of insulin in endogenous hypertriglyceridemia. J Clin Invest 1967, 46:1756-1767.

79. Mayes PA: Intermediary metabolism of fructose. Am J Clin Nutr 1993, 58:754S-765S

80. Miyazaki M, Dobrzyn A, Man WC, et al: Stearoyl-CoA desaturase 1 gene expression is necessary for fructose-mediated induction of lipogenic gene expression by sterol regulatory element-binding protein-1cdependent and -independent mechanisms. J Biol Chem 2004, 279:25164-71.

81. Matsuzaka T, Shimano $H$, Yahagi N, et al: Insulin-independent induction of sterol regulatory element-binding protein-1c expression in the livers of streptozotocin-treated mice. Diabetes 2004, 53:560-9.

82. Nagai $Y$, Nishio $Y$, Nakamura $T$, Maegawa $H$, Kikkawa R, Kashiwagi $A$ : Amelioration of high fructose-induced metabolic derangements by activation of PPARalpha. Am J Physiol Endocrinol Metab 2002, 282: E1180-90.

83. Bergheim I, Weber S, Vos M, et al: Antibiotics protect against fructoseinduced hepatic lipid accumulation in mice: role of endotoxin. $J$ Hepatol 2008, 48:983-92.

84. Rizkalla SW, Alamowitch C, Luo J, et al: Effect of dietary fish oil on insulin action in fat cells of control and non-insulin-dependent diabetic rats. Ann N Y Acad Sci 1993, 213-217.

85. Rizkalla SR, Hellal I, Boillot J, et al: Comparative metabolic effects of 10 week starch, glucose, fructose in normal rats. In Insulin and the Cell Membrane. Edited by: Klimes I, Howard BV, Kahn CR. New York: Gordon an Breach Sci; 1990:443-450, New York 1990 ed.

86. Jurgens $\mathrm{H}$, Haass $W$, Castaneda TR, et al: Consuming fructose-sweetened beverages increases body adiposity in mice. Obes Res 2005, 13:1146-56.

87. Chevalier MM, Wiley JH, Leveille GA: Effect of dietary fructose on fatty acid synthesis in adipose tissue and liver of the rat. J Nutr 1972, 102:337-342.

88. Blakely SR, Akintilo AO, Pointer RH: Effects of fructose, levamisole and vanadate on insulin action in rat adipose tissue. J Nutr 1987, 117:559-566.

89. Bocarsly ME, Powell ES, Avena NM, Hoebel BG: High-fructose corn syrup causes characteristics of obesity in rats: Increased body weight, body fat and triglyceride levels. Pharmacol Biochem Behav 2010, 97(1):101-6.

90. Pagliassotti MJ, Prach PA, Koppenhafer TA, Pan DA: Changes in insulin action, triglycerides, and lipid composition during sucrose feeding in rats. Am J Physiol 1996, 271:R1319-26.

91. Chong MF-F, Fielding BA, Frayn KN: Mechanisms for the acute effect of fructose on postprandial lipemia. Am J Clin Nutr 2007, 85:1511-1520.

92. Teff KL, Grudziak J, Townsend RR, et al: Endocrine and metabolic effects of consuming fructose- and glucose-sweetened beverages with meals in obese men and women: influence of insulin resistance on plasma triglyceride responses. J Clin Endocrinol Metab 2009, 94:1562-9.

93. Delarue J, Normand S, Pachiaudi C, Beylot M, Lamisse F, Riou J: The contribution of naturally labelled $13 \mathrm{C}$ fructose to glucose appearance in humans. Diabetologia 1993, 36:338-45

94. Swarbrick MM, Stanhope KL, Elliott SS, et al: Consumption of fructosesweetened beverages for 10 weeks increases postprandial triacylglycerol and apolipoprotein-B concentrations in overweight and obese women. British Journal of Nutrition 2008, 100:947-952.

95. Guthrie JF, Morton JF: Food sources of added sweeteners in the diets of Americans. J Am Diet Assoc 2000, 100:43-51, quiz 49-50.

96. Le KA, Ith $M$, Kreis $R$, et al: Fructose overconsumption causes dyslipidemia and ectopic lipid deposition in healthy subjects with and without a family history of type 2 diabetes. Am J Clin Nutr 2009, 89:1760-5.

97. Tappy L, Randin JP, Felber JP, et al: Comparison of thermogenic effect of fructose and glucose in normal humans. Am J Physiol 1986, 250:E718-24.

98. Abdel-Sayed A, Binnert C, Le KA, Bortolotti M, Schneiter P, Tappy L: A highfructose diet impairs basal and stress-mediated lipid metabolism in healthy male subjects. Br J Nutr 2008, 100:393-9. 
99. MacDonald I: Influence of fructose and glucose on serum lipid levels in men and pre and post-menopausal women. Am J Clin Nutr 1966, 18:369-373.

100. Hallfrisch J, Ellwood KC, Michaelis OEt, Reiser S, O'Dorisio T, Prather E: Effects of dietary fructose on plasma glucose and hormone responses in normal and hyperinsulinemic men. J Nutr 1983, 113:1819-1826.

101. Hallfrisch J, Reiser S, Phrather ES: Blood lipid distribution of hyperinsulinemic men consuming three levels of fructose. Am J Clin Nutr 1983, 37:740-748.

102. Reiser S, Powell AS, Scholfield DJ, Panda P, Fields M, Canary JJ: Day-long glucose, insulin, and fructose responses of hyperinsulinemic and nonhyperinsulinemic men adapted to diets containing either fructose or high-amylose cornstarch. Am J Clin Nutr 1989, 50:1008-1014.

103. Bantle J, Raatz S, Thomas W, Georgopoulos A: Effects of dietary fructose on plasma lipids in healthy subjects. Am J Clin Nutr 2000, 72:1128-34.

104. Hollenbeck C: Dietary fructose effects on lipoprotein metabolism and risk for coronary artery disease. Am J Clin Nutr 1993, 58:800S-809.

105. Stanhope K, Havel P: Fructose consumption: potential mechanisms for its effects to increase visceral adiposity and induce dyslipidemia and insulin resistance. Curr Opin Lipidol 2008, 19:16-24.

106. Fung TT, Malik V, Rexrode KM, Manson JE, Willett WC, Hu FB: Sweetened beverage consumption and risk of coronary heart disease in women. Am J Clin Nutr 2009, 89:1037-42.

107. Domel SB, Thompson WO, Baranowski T, Smith AF: How children remember what they have eaten. Journal of the American Dietetic Association 1994, 94:1267-1272.

108. Rockett $\mathrm{H}$, Colditz G: Assessing diets of children and adolescents. Am J Clin Nutr 1997, 65:11165-1122.

109. Nordestgaard BG, Benn M, Schnohr P, Tybjaerg-Hansen A: Nonfasting Triglycerides and Risk of Myocardial Infarction, Ischemic Heart Disease, and Death in Men and Women. JAMA 2007, 298:299-308.

110. Huttunen J: Serum lipids, uric acid and glucose during chronic consumption of fructose and xylitol in healthy human subjects. Int $Z$ Vitam Ernahrungsforsch Beih 1976, 15:105-15.

111. Sievenpiper $\mathrm{J}$, Carleton AJ, Chatha S, et al: Heterogeneous effects of fructose on blood lipids in individuals with type 2 diabetes: systematic review and meta-analysis of experimental trials in humans. Diabetes Care 2009, 32:1930-7.

112. Grigoresco C, Rizkalla S, Halfon P, et al: Lack of detectable deleterious effects on metabolic control of daily fructose ingestion for 2 months in NIDDM patients. Diabetes Care 1988, 11:546-550.

113. Koivisto $\mathrm{V}$, Yki-Järvinen $\mathrm{H}$ : Fructose and insulin sensitivity in patients with type 2 diabetes. J Intern Med 1993, 233:145-53.

114. Bantle JP, Laine DC, Thomas JW: Metabolic effects of dietary fructose and sucrose in types I and II diabetic subjects. Jama 1986, 256:3241-6.

115. Thorburn A, Crapo P, Beltz W, Wallace P, Witztum J, Henry R: Lipid metabolism in non-insulin-dependent diabetes: effects of long-term treatment with fructose-supplemented mixed meals. Am J Clin Nutr 1989, 50:1015-1022.

116. Malerbi DA, Paiva ES, Duarte AL, Wajchenberg BL: Metabolic effects of dietary sucrose and fructose in type II diabetic subjects. Diabetes Care 1996, 19:1249-56.

117. American Diabetes Association: Nutrition Recommendations and Interventions for Diabetes: A position statement of the American Diabetes Association. Diabetes Care 2007, 30:548-65.

118. American Diabetes Association: Nutrition Recommendations and Interventions for Diabetes: A position statement of the American Diabetes Association. Diabetes Care 2008, 31:561-78.

119. Kanarek RB, Orthen-Gambill N: Differential effect of sucrose, fructose and glucose on carbohydrate-induced obesity in rats. J Nutr 1982, 112:1546-1554.

120. Thorburn AW, Storlien LH, Jenkins AB, Khouri S, Kraegen EW: Fructoseinduced in vivo insulin resistance and elevated plasma triglyceride levels in rats. Am J Clin Nutr 1989, 49:1155-1163.

121. Catena C, Giacchetti G, Novello M, Colussi G, Cavarape A, Sechi LA: Cellular mechanisms of insulin resistance in rats with fructose-induced hypertension. Am J Hypertens 2003, 16:973-8.

122. Bezerra RM, Ueno M, Silva MS, Tavares DQ, Carvalho CR, Saad MJ: A high fructose diet affects the early steps of insulin action in muscle and liver of rats. J Nutr 2000, 130:1531-5.
123. Maiztegui B, Borelli Ml, Raschia MA, Del Zotto H, Gagliardino JJ: Islet adaptive changes to fructose-induced insulin resistance: beta-cell mass, glucokinase, glucose metabolism, and insulin secretion. J Endocrinol 2009, 200:139-49.

124. Cummings BP, Stanhope KL, Graham JL, et al: Dietary Fructose Accelerates the Development of Diabetes in UCD-T2DM Rats: Amelioration by the Antioxidant, \{alpha\}-Lipoic Acid. Am J Physiol Regul Integr Comp Physiol 2010, 298:R1343-R1350

125. Mielke JG, Taghibiglou C, Liu L, et al: A biochemical and functional characterization of diet-induced brain insulin resistance. J Neurochem 2005, 93:1568-78.

126. Avramoglu RK, Qiu W, Adeli K: Mechanisms of metabolic dyslipidemia in insulin resistant states: deregulation of hepatic and intestinal lipoprotein secretion. Front Biosci 2003, 8:d464-76.

127. Pooranaperundevi $M$, Sumiyabanu MS, Viswanathan $P$, Sundarapandiyan $R$ Anuradha CV: Insulin resistance induced by high-fructose diet potentiates carbon tetrachloride hepatotoxicity. Toxicol Ind Health 26:89-104

128. Crapo A, Insel J, Sperling M, Kolterman G: Comparison of serum glucose, insulin and glucagon responses to different types of complex carbohydrate in non insulin-dependent diabetic patients. Am J Clin Nutr 1981, 34:184-190.

129. Simonson DC, Tappy L, Jequier E, Felber JP, DeFronzo RA: Normalization of carbohydrate-induced thermogenesis by fructose in insulin-resistant states. Am J Physiol 1988, 254:E201-7.

130. Dirlewanger $M$, Schneiter $P$, Jequie $E$, Tappy $L$ : Effects of fructose on hepatic glucose metabolism in humans. Am J Physiol Endocrinol Metab 2000, 279:E907-11.

131. Beck-Nielsen H, Pederson O, Lindskov HO: Impaired cellular insulin binding and insulin sensitivity induced by high-fructose feeding in normal subjects. Am J Clin Nutr 1980, 33:273-278.

132. Rizkalla SW, Lebouc Y, Serog P, Apfelbaum M: Carbohydrate intake affects insulin binding to human erythrocytes in normal weight subjects but not in subjects with familly obesity. Metabolism 1981, 30:900-907.

133. Bossetti B, Kocher L, Moranz J, Falko J: The effects of physiologic amounts of simple sugars on lipoprotein, glucose, and insulin levels in normal subjects. Diabetes Care 1984, 7(4):309-12.

134. Crapo PA, Kolterman OG: The metabolic effects of 2-week fructose feeding in normal subjects. Am J Clin Nutr 1984, 39:525-534.

135. Lê K, Faeh D, Stettler R, et al: Effects of four-week high-fructose diet on gene expression in skeletal muscle of healthy men. Diabetes Metab 2008, 34:82-5.

136. Couchepin C, Lê K, Bortolotti M, et al: Markedly blunted metabolic effects of fructose in healthy young female subjects compared with male subjects. Diabetes Care 2008, 31:1254-6.

137. Blayo A, Fontvieille AM, Rizkalla SW, Bruzzo F, Slama G: Effets métaboliques de la consommation quotidienne pendant un an de saccharose ou de fructose par des diabétiques. Médecine et Nutrition 1990, 26:11-14.

138. Osei K, Falko J, Bossetti B, Holland G: Metabolic effects of fructose as a natural sweetener in the physiologic meals of ambulatory obese patients with type II diabetes. Am J Med 1987, 83:249-55.

139. Osei K, Bossetti B: Dietary fructose as a natural sweetener in poorly controlled type 2 diabetes: a 12-month crossover study of effects on glucose, lipoprotein and apolipoprotein metabolism. Diabet Med 1989, 6:506-11.

140. Wu T, Giovannucci E, Pischon T, et al: Fructose, glycemic load, and quantity and quality of carbohydrate in relation to plasma C-peptide concentrations in US women. Am J Clin Nutr 2004, 80:1043-9.

141. Janket SJ, Manson JE, Sesso H, Buring JE, Liu S: A prospective study of sugar intake and risk of type 2 diabetes in women. Diabetes Care 2003, 26:1008-15.

142. Paganus A, Mäenpää J, Akerblom H, Stenman U, Knip M, Simell O: Beneficial effects of palatable guar and guar plus fructose diets in diabetic children. Acta Paediatr Scand 1987, 76:76-81.

143. Donmoyer CM, Ejiofor J, Lacy DB, Chen SS, McGuinness OP: Fructose augments infection-impaired net hepatic glucose uptake during TPN administration. Am J Physiol Endocrinol Metab 2001, 280:E703-711.

144. Moore M, Davis S, Mann S, Cherrington A: Acute fructose administration improves oral glucose tolerance in adults with type 2 diabetes. Diabetes Care 2001, 24:1882-7. 
145. Petersen KF, Laurent D, Yu C, Cline GW, Shulman GI: Stimulating Effects of Low-Dose Fructose on Insulin-Stimulated Hepatic Glycogen Synthesis in Humans. Diabetes 2001, 50:1263-1268.

146. Clement K, Pueyo ME, Vaxillaire M, et al: Assessment of insulin sensitivity in glucokinase-deficient subjects. Diabetologia 1996, 39:82-90.

147. Brown CM, Dulloo AG, Yepuri G, Montani J-P: Fructose ingestion acutely elevates blood pressure in healthy young humans. Am J Physiol Regul Integr Comp Physiol 2008, 294:R730-737.

148. Barone BB, Wang NY, Bacher AC, Stewart KJ: Decreased exercise blood pressure in older adults after exercise training: contributions of increased fitness and decreased fatness. Br J Sports Med 2009, 43:52-6.

149. Forman J, Choi H, Curhan G: Fructose and Vitamin C Intake Do Not Influence Risk for Developing Hypertension. J Am Soc Nephrol 2009, 20:863-71.

150. Choi HK, Curhan G: Soft drinks, fructose consumption, and the risk of gout in men: prospective cohort study. BMJ 2008, 336:309-312.

151. Crapo P, Kolterman O: The metabolic effects of 2-week fructose feeding in normal subjects. Am J Clin Nutr 1984, 39(4):525-34.

152. Emmerson B: Effect of oral fructose on urate production. Ann Rheum Dis 1974, 33:276-80

153. Menghini S, E DC: Evaluation of hyperuricemia caused by fructose in a status of altered uric acid metabolism quad Sclavo Diagn. 1987, 23:441-6.

154. Ravich WJ, Bayless TM, Thomas M: Fructose: incomplete intestinal absorption in humans. Gastroenterology 1983, 84:26-9.

155. Massicotte D, Peronnet F, Allah C, Hillaire-Marcel C, Ledoux M, Brisson G Metabolic response to [13C]glucose and [13C]fructose ingestion during exercise. J Appl Physiol 1986, 61:1180-4.

156. Jandrain BJ, Pallikarakis N, Normand S, et al: Fructose utilization during exercise in men: rapid conversion of ingested fructose to circulating glucose. J Appl Physiol 1993, 74:2146-54.

157. Fujisawa T, Mulligan K, Wada L, Schumacher L, Riby J, Kretchmer N: The effect of exercise on fructose absorption. Am J Clin Nutr 1993, 58:75-9.

158. Adopo E, Peronnet F, Massicotte D, Brisson GR, Hillaire-Marcel C: Respective oxidation of exogenous glucose and fructose given in the same drink during exercise. J Appl Physiol 1994, 76:1014-9.

159. Riddell MC, Bar-Or O, Wilk B, Parolin ML, Heigenhauser GJ: Substrate utilization during exercise with glucose and glucose plus fructose ingestion in boys ages 10-14 yr. J Appl Physiol 2001, 90:903-11.

160. Brundle S, Thayer R, Taylor AW: Comparison of fructose and glucose ingestion before and during endurance cycling to exhaustion. J Sports Med Phys Fitness 2000, 40:343-9.

161. Holbrook J, Smith JJ, S R: Dietary fructose or starch: effects on copper, zinc, iron, manganese, calcium, and magnesium balances in humans. Am J Clin Nutr 1989, 49(6):1290-4.

162. Pavlic M, Libiseller K, Grubwieser P, Ulmer H, Sauper T, Rabl W: Another 'soberade' on the market: does Outox keep its promise? Wien Klin Wochenschr. 2007, 119:104-11.

163. Dolan LC, Potter SM, Burdock GA: Evidence-based review on the effect of normal dietary consumption of fructose on development of hyperlipidemia and obesity in healthy, normal weight individuals. Crit Rev Food Sci Nutr 2010, 50:53-84.

164. FDA-CFSAN: Guidance for Industry. Evidence-based review system for the scientific evaluation of health claims.US Food and Drug Administration (FDA). Center for food safety and Applied Nutrition (CFSAN). College Park, MD; 2009, 1-26.

\section{Submit your next manuscript to BioMed Central and take full advantage of:}

- Convenient online submission

- Thorough peer review

- No space constraints or color figure charges

- Immediate publication on acceptance

- Inclusion in PubMed, CAS, Scopus and Google Scholar

- Research which is freely available for redistribution

Submit your manuscript at www.biomedcentral.com/submit
Biomed Central 